\title{
Recently Emerged Myxosporean Encephalomyelitis of Cultured Yellowtail Seriola quinqueradiata in Japan
}

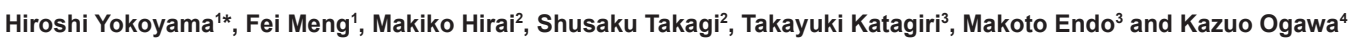 \\ ${ }^{1}$ Department of Aquatic Bioscience, Graduate School of Agricultural and Life Sciences, The University of Tokyo, Tokyo, Japan \\ ${ }^{2}$ Ehime Prefectural Fisheries Experimental Station, Uwajima, Ehime, Japan \\ ${ }^{3}$ Laboratory of Fish Health Management, Tokyo University of Marine Science and Technology, Tokyo, Japan \\ ${ }^{4}$ Meguro Parasitological Museum, Tokyo, Japan
}

\begin{abstract}
Encephalomyelitis associated with developmental stages of a myxosporean parasite has recently occurred in cultured yellowtail Seriola quinqueradiata from western Japan. Although mature spore stages of the parasite were not found in the spinal cord, the myxosporean was molecularly identified as Myxobolus spirosulcatus by the 18S rDNA analysis and in situ hybridization and has been previously reported as a non-pathogenic parasite infecting the bile duct of yellowtail. However, the causal relationship between the encephalomyelitis and $M$. spirosulcatus is still controversial. Typical signs of the disease were reduced feeding, erratic and abnormal swimming, skin ulceration from the jaw to the abdomen, and redness of the brain. Histopathologically, this disease was characterized by 1 ) gliosis and multi-focal glial nodules, 2) nerve cell necrosis with neurophagia, 3) blood congestion and hemorrhages in the central nervous tissue, 4) swollen eosinophilic nerve fibers and degenerative axons. In the present study, we conducted further histopathological observations and tried to determine the disease mechanisms in relation to water temperature and feeding regimes. It was indicated that developing plasmodia directly caused the gliosis and glial nodules in the nervous system. Fluctuating water temperature was suggested to be partly responsible for disease outbreak. Detection rates of $M$. spirosulcatus spores in the bile were significantly higher in the constant temperature groups than those in the fluctuating temperature groups. Further studies on the biology of $M$. spirosulcatus are required to implement a management strategy to the myxosporean encephalomyelitis of yellowtail.
\end{abstract}

\section{Introduction}

According to the latest statistics by the Ministry of Agriculture, Forestry and Fisheries, Japan, the annual production of cultured yellowtail is 100,625 tonnes, making a profit of approximately 100 billion Japanese yen (approx. 1,300,000 US dollar). The main location of yellowtail farming is in the western part of Japan, e.g., Kagoshima, Ehime, Nagasaki, Oita and Kochi Prefectures. Most fish farmers use wild-captured yellowtail fingerlings, while some farmers use hatcheryreared ones. A new disease characterized by encephalomyelitis has recently occurred in cultured yellowtail Seriola quinqueradiata from western Japan. Typical signs of the disease were reduced feeding, erratic and abnormal swimming, skin ulceration from the jaw to the anterior abdomen, and redness of the brain. According to Katagiri et al. [4], this disease was definitively diagnosed by the following histopathological lesions; 1) gliosis and multi-focal glial nodules in the brain and spinal cord, 2) nerve cell necrosis with neurophagia, 3) blood congestion and hemorrhages in the central nervous tissue, 4) swollen eosinophilic nerve fibers and degenerative axons. The present disease was first found in juvenile yellowtail cultured in Ehime Prefecture in the summer of 2003. At that time, the cumulative mortality reached approx. $14 \%$ in net pen. In 2004, the disease also occurred in older fish (1-year old fish), and the geographical distribution expanded to other areas. Since 2005 fish mortality has gradually decreased (less than 10\%), but a remarkable retardation in growth rate has been observed and continues to make this disease a serious problem for fish farmers.

Recent studies revealed that the encephalomyelitis of yellowtail was associated with a myxosporean parasite. Bacteriological and virological tests on affected fish yielded no significant findings, and trials of experimental transmission of the disease by intraperitoneal injection of brain homogenates from diseased fish were unsuccessful. The multinuclear organisms, possibly developmental stages of a myxosporean parasite, were consistently found in the spinal cord of diseased fish, implying that a myxosporean was the causative agent of the disease. However, the parasite was unidentified due to the lack of mature spore stages. Subsequently, the myxosporean in the spinal cord of diseased yellowtail was molecularly identified as Myxobolus spirosulcatus by $18 \mathrm{~S}$ rDNA analysis and in situ hybridization [9] and has been previously reported as a non-pathogenic parasite infecting the bile duct of yellowtail [6].

However, the causal relationship between the encephalomyelitis and a myxosporean parasite is still controversial. One question is that there appears to be an insufficient number of parasites as compared with severity of the disease. Nevertheless, this problem may be explained by the Wallerian degeneration; the degeneration of axons distal to a site of injury [1]. The pathological changes observed in the central nervous system might have been caused by the lesions due to parasites infecting the peripheral nervous system. Another question is that there are found to be many subclinically infected fish, but this phenomenon may be interpreted as a facultative disease which needs some unknown disease-inducing factors. Empirical observations suggested that the disease occurred in association with satiation feeding and fluctuating water temperature. Due to frequent influx of warm water originating

*Corresponding authors: Hiroshi Yokoyama, Department of Aquatic Bioscience Graduate School of Agricultural and Life Sciences, The University of Tokyo, Yayo 1-1-1, Bunkyo, Tokyo 113-8657, Japan; E-mail: ayokoh@mail.ecc.u-tokyo.ac.jp

Received October 04, 2011; Accepted December 08, 2011; Published December 17, 2011

Citation: Yokoyama H, Meng F, Hirai M, Takagi S, Katagiri T, et al.(2011) Recently Emerged Myxosporean Encephalomyelitis of Cultured Yellowtail Seriola quinqueradiata in Japan. J Aquac Res Development S2:004. doi:10.4172/2155 9546.S2-004

Copyright: (c) 2011 Yokoyama $\mathrm{H}$, et al.This is an open-access article distributed under the terms of the Creative Commons Attribution License, which permits unrestricted use, distribution, and reproduction in any medium, provided the original author and source are credited. 
Citation: Yokoyama H, Meng F, Hirai M, Takagi S, Katagiri T, et al.(2011) Recently Emerged Myxosporean Encephalomyelitis of Cultured Yellowtail Seriola quinqueradiata in Japan. J Aquac Res Development S2:004. doi:10.4172/2155-9546.S2-004

Page 2 of 4

from the Kuroshio Current, water temperature in the middle and southern areas of the Uwa Sea where are enzootic for the disease is known to fluctuate by as much as more than $2-3^{\circ} \mathrm{C}$ within a few days.

The present disease appears to have a lot of common features with the parasitic encephalitis of farmed Atlantic salmon Salmo salar found in Ireland between 1992 and 1994 [7,8,2,3]. Parasitic encephalitis found in the brain of Atlantic salmon was associated with developmental stages of Myxobolus cerebralis [3]. Similarities to the present disease are that no mature spores were detected in the central nervous system and the presence of the parasite was not always associated with clinical signs of the disease. A variety of environmental factors, e.g., water temperature were also suggested to cause the variability and severity of neurological signs in affected Atlantic salmon [2]. This paper aims to support the etiology for the encephalomyelitis of yellowtail and to determine the disease-inducing factor using subclinically infected fish.

\section{Materials and Methods}

\section{Fish}

Naturally affected yellowtail were collected at fish farms in Ehime Prefecture in August 2009 ( $\mathrm{n}=5$, 1-year class, $1642 \mathrm{~g}$ in mean body weight, $49.7 \mathrm{~cm}$ in mean body length) and Kagoshima Prefecture in September 2009 ( $\mathrm{n}=10,0$-year class, $290.4 \mathrm{~g}$ in mean body weight, $28.0 \mathrm{~cm}$ in mean body length). All these fish displayed typical signs of the disease (Figure 1). Diseased fish from Ehime Prefecture exhibited ulceration in the mouth, redness in the brain, congestion in the liver, green liver, and redness in the pyloric caecum. Compared to the fish from Ehime, affected fish from Kagoshima exhibited more severe hemorrhages or ulceration in the head, eyes, mouth, and around pectoral fins. Hemorrhages in the brain were rather rare in seriously diseased fish with bloody eyes. After dissection, the brain and the spinal cord were collected and fixed in $10 \%$ neutral formalin for histology, and the medulla oblongata were fixed in $70 \%$ ethanol for PCR.

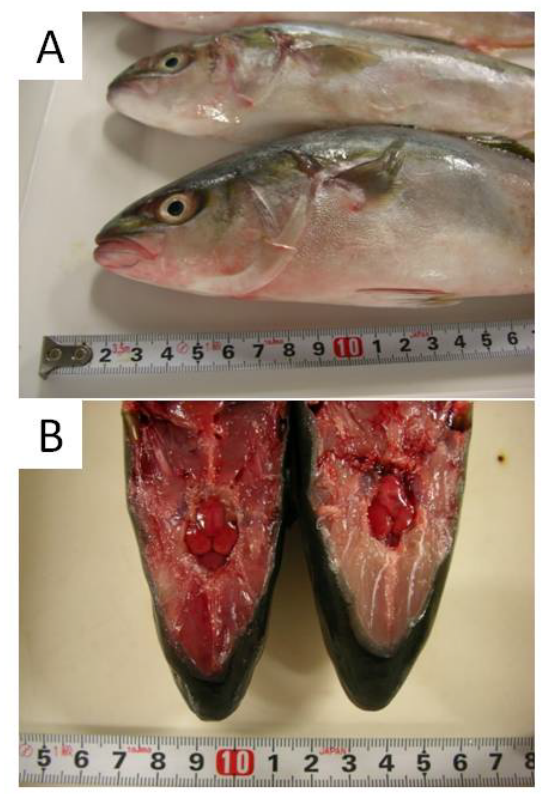

Figure 1: Gross observation of affected yellowtail. Note the skin ulceration from the jaw to the anterior abdomen $(A)$, and redness of the brain $(B)$.

\section{Histopathology}

Formalin-fixed spinal cord were embedded in paraffin and cut at $5 \mu \mathrm{m}$ or $10 \mu \mathrm{m}$ for hematoxylin and eosin (H\&E) or Kluver-Barrera staining, respectively. Number of myxosporean plasmodia was counted in H\&E stained-sections (randomly selected 3-10 sections) and intensity of infection was defined as the number of parasite per one histological section (number of parasite/section). Histopathological lesions were classified as the following four parameters; 1) gliosis in the brain and spinal cord, 2) nerve cell necrosis with neurophagia, 3) blood congestion and hemorrhages in the central nervous tissue, and 4) swollen eosinophilic nerve fibers and degenerative axons [4]. Each parameter was semiquantitatively valued from $1+$ to $3+$. Lesion score for individual fish was defined as addition of the four histopathological values.

\section{PCR}

DNA was extracted from ethanol-fixed medulla oblongata or spinal cord using a QIAamp DNA Mini Kit (Qiagen, Hilden, Germany) according to the manufacturer's protocol. PCR tests were conducted following the protocol previously described by Yokoyama et al. [9]. Briefly, PCR reactions were carried out in $20 \mu$ of total volume. The PCR primers specific for M. spirosulcatus, MUKf1 (5'-TGC ACT GCG TGT TCG CA-3') and MUKr2 (5'-CTC CTT GCT CCC GGC TT-3') were used. Each PCR mixture contained $0.1 \mu$ of Takara Ex TaqTM HS ( $5 \mathrm{U} / \mu \mathrm{l}), 2 \mu \mathrm{l}$ of $10 \times$ Ex Taq Buffer, $1.6 \mu \mathrm{l}$ of dNTP mixture (2.5 $\mathrm{mM}$ each), $0.6 \mu \mathrm{l}$ of each primer $(25 \mathrm{pM} / \mu \mathrm{l})$ and $1.0 \mu \mathrm{l}$ of extracted DNA suspension. All PCR reactions were performed in an iCycler (Bio-Rad, Hercules, CA, USA). Denaturation of DNA $\left(95^{\circ} \mathrm{C}\right.$ for 10 min) was followed by 35 cycles of amplification consisting of $30 \mathrm{~s}$ for denaturation at $95^{\circ} \mathrm{C}, 30 \mathrm{~s}$ for annealing at $57^{\circ} \mathrm{C}$ and $30 \mathrm{~s}$ for extension at $74^{\circ} \mathrm{C}$, and ended by a $7-\mathrm{min}$ extension at $74^{\circ} \mathrm{C}$. PCR products were analyzed by $1.5 \%$ agarose gel electrophoresis with TAE (40 mM Trisacetate, 1mM EDTA) running buffer and visualized with SYBR Safe DNA gel stain (Invitrogen, Carlsbad, CA, USA). Expected size of amplicon for the PCR was $860 \mathrm{bp}$.

\section{Bile infection}

From the samples of Ehime Prefecture, bile was collected using a syringe and kept individually in a $1.5-\mathrm{ml}$ tube. After bile samples were centrifuged at $400 \times \mathrm{g}$ for $5 \mathrm{~min}$, supernatants were discarded. The pellets were re-suspended in $0.1 \mathrm{ml}$ of physiological saline and wet mount preparation of the suspension was examined for spores of $M$. spirosulcatus by light microscopy.

\begin{tabular}{|l|l|l|l|l|}
\hline & \multicolumn{2}{|l|}{$\begin{array}{l}\text { Fluctuating temperature be- } \\
\text { tween } 24^{\circ} \mathrm{C} \text { and } 29^{\circ} \mathrm{C}\end{array}$} & \multicolumn{2}{l|}{ Constant temperature at $24^{\circ} \mathrm{C}$} \\
\cline { 2 - 5 } & $\begin{array}{l}\text { Satiation } \\
\text { feeding }\end{array}$ & $\begin{array}{l}\text { Regulated } \\
\text { feeding }\end{array}$ & $\begin{array}{l}\text { Satiation } \\
\text { feeding }\end{array}$ & $\begin{array}{l}\text { Regulated } \\
\text { feeding }\end{array}$ \\
\hline $\begin{array}{l}\text { Cumulative } \\
\text { mortality (\%) }\end{array}$ & $4^{\mathrm{a}}$ & $3^{\mathrm{a}}$ & $1^{\mathrm{b}}$ & $0^{\mathrm{b}}$ \\
\hline $\begin{array}{l}\text { Prevalence of } \\
\text { infection in spi- } \\
\text { nal cord (\%) }\end{array}$ & 100 & 100 & 90 & 100 \\
\hline $\begin{array}{l}\text { Detection rate } \\
\text { of spores in } \\
\text { bile (\%) }\end{array}$ & $30^{\mathrm{a}}$ & $20^{\mathrm{a}}$ & $80^{\mathrm{b}}$ & $75^{\mathrm{b}}$ \\
\hline
\end{tabular}

Table 1: Mortality due to the myxosporean encephalomyelitis and percentage of infection with Myxobolus spirosulcatus in yellowtail kept with different temperature and feeding conditions. Infections in the spinal cord and bile were investigated by PCR and microscopy, respectively. Different letters ( $a$ and $b$ ) in the columns on the mortality and detection rate mean significant differences among different groups $(P<0.05$; Ryan's test) 
Citation: Yokoyama H, Meng F, Hirai M, Takagi S, Katagiri T, et al.(2011) Recently Emerged Myxosporean Encephalomyelitis of Cultured Yellowtail Seriola quinqueradiata in Japan. J Aquac Res Development S2:004. doi:10.4172/2155-9546.S2-004

\section{Disease mechanisms}

Subclinically infected yellowtail juveniles $(n=400)$ were transferred from a fish farm in a northern part of the Uwa Sea to the laboratory of Ehime Prefectural Fisheries Experimental Station on 31 August, 2009. Before the transportation, the stock of yellowtail juveniles was confirmed to be infected with $M$. spirosulcatus in the medulla oblongata by PCR assay (10 positive fish out of 10 examined fish). Fish were equally divided into four land-based tanks of 3.8 metric ton (each 100 fish) equipped with ultraviolet irradiation with sandfiltered seawater. A combination of the two different experimental conditions in water temperature and feeding regimes was set up for the four groups (Table 1). For the fluctuating temperature groups, water temperature was increased from $24^{\circ} \mathrm{C}$ to $29^{\circ} \mathrm{C}$ and then decreased from $29^{\circ} \mathrm{C}$ to $24^{\circ} \mathrm{C}$ within about 2 weeks. The fluctuating cycle was repeated six times during the experimental period. For the constant temperature groups, water temperature was controlled at $24^{\circ} \mathrm{C}$. Fish of

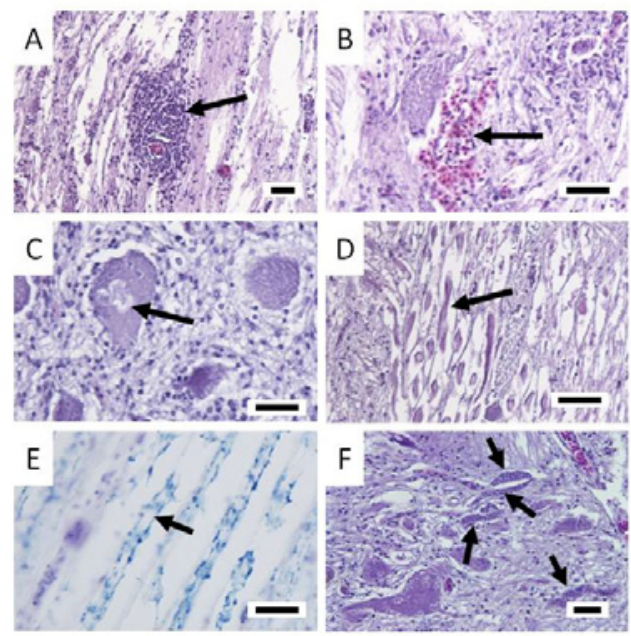

Figure 2: Histopathological sections of the central nervous system of affected yellowtail. A-D and F: H \& E stain, E: Kluver-Barrera stain. Arrows show the glial nodule (A), blood congestion and hemorrhages (B), nerve cell necrosis with neurophagia $(C)$, swollen eosinophilic nerve fibers (D), demyelination caused by degenerative neurons $(E)$, and clusters of elongated myxosporean plasmodia $(F)$ in the brain and spinal cord. Scale bars $=30 \mu \mathrm{m}$
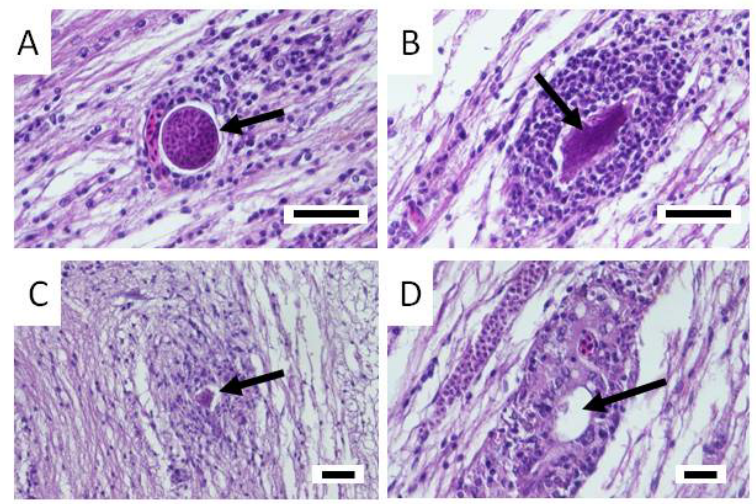

Figure 3: Histopathological sections of glial nodules in the central nervous system of affected yellowtail. $H$ \& $E$ stain. Arrows show degenerating plasmodia of the myxosporean (A-C), and a hole-like structure (D) possibly due to loss of the parasite in the center of the glial nodule. Scale bars $=30 \mu \mathrm{m}$.

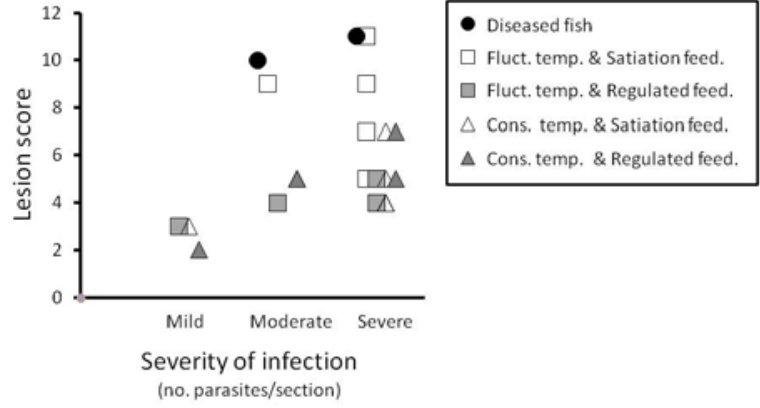

Figure 4: Relationship between the severity of infection (no. of parasite/section; mild: 1-5, moderate: 6-10, severe: >11) and the lesion score for each yellowtail reared in different temperature (fluctuating or constant) and feeding (satiation or regulated) conditions. Two diseased fish were from the fluctuating temperature + satiation feeding group (11 in intensity of infection) and the fluctuating temperature + regulated feeding group (10 in intensity of infection).

the satiation feeding group were fed commercial pellet diet to satiation, whereas fish of the restricted feeding group were fed a half amount of the pellet diet to the regularly given feeds. During the rearing period for 88 days (from 1 September to 27 November, 2009), fish morbidity due to the encephalomyelitis was recorded. Two diseased fish were collected before death and investigated histopathologically. At the end of the experiment, 10 fish from each tank were examined for $M$. spirosulcatus infection in the medulla oblongata and the gallbladder by PCR and microscopic observation, respectively. Four to five fish out of the 10 fish were also examined by histopathology. Intensity of infection and lesion score were evaluated in histological sections described above. According to the intensity of infection, the severity of infection (number of parasite / section) was graded as mild (1-5), moderate (6$10)$, or severe (>11). Statistical analysis with Ryan's test was conducted on the cumulative mortality and the detection rate of myxospores in the bile.

\section{Results}

All diseased fish of Ehime Prefecture were found to be positive by PCR assay (5 out of 5 fish), whereas no spores of $M$. spirosulcatus were observed from the gallbladder. Histopathologically, moderate lesions in gliosis, glial nodules and swollen nerve fibers and degenerative axons were observed, but blood congestion and hemorrhages were not found. Mean intensity of infection was 0.3 (no. of parasites/ section), and mean lesion score was 5.4. All diseased fish of Kagoshima Prefecture were positive by PCR (10 out of 10 fish). Mean intensity of infection was 14.1 (no. of parasites/section), and mean lesion score was 7.8. Histopathological observations showed highly extensive hemorrhages and congestions with high density of plasmodia, and demyelination caused by degenerative neurons (Figure 2E). Degenerating myxosporean plasmodia was found to be located in the center of glial nodules (Figures $3 \mathrm{~A}-\mathrm{C}$ ), indicating that the gliosis was an inflammatory response to the myxosporean. Plasmodia became necrotic and atrophied, and finally disappeared, resulting in a hole-like appearance in the center of glial nodules (Figure 3D).

In the experiment of disease mechanisms, disease rates were overall low (1-4\%) in all groups, but morbidities of the fluctuating temperature groups were significantly higher than those of the constant temperature groups (Table 1). However, morbidities were not significantly different between satiation and regulated feeding groups. Prevalence of infection with M. spirosulcatus in the spinal cord was 
$100 \%$ except one group (constant temperature + satiation feeding). Detection rates of M. spirosulcatus spores in the bile were $20-30 \%$ for the fluctuating temperature groups, but were $75-80 \%$ for the constant temperature groups. Histopathological observation showed that as the infection became severe, the lesion score tended to increase, though lesion scores in fish with high intensity varied widely (Figure 4). It is notable that the two diseased fish (one from fluctuating temperature + regulated feeding group, and the other from fluctuating temperature + satiation feeding group) had considerably high lesion scores (10 and 11 , respectively).

\section{Discussion}

In the present study, the causal relationship between the myxosporean and the disease is strongly supported by the following 3 points; 1) Myxobolus spirosulcatus was consistently detected from diseased fish. 2) Heavily diseased fish tend to have a high intensity of infection with M. spirosulcatus. 3) Histopathological observation showed that the plasmodia of $M$. spirosulcatus were found in the gliosis and glial nodules which were the typical character of the disease. The rapid disappearance of degenerate plasmodia may explain the relatively low number of parasites observed for the severity of the disease. The low intensity of infection in Ehime samples (1-year old) might have been underestimated due to loss of the parasites. Two-host life cycles involving fish and annelids have been elucidated for more than 30 myxosporean species [5], however, scarce knowledge on the life cycle of marine myxosporeans does not allow experimental infection of the parasites, resulting in difficulty of proving the cause and effect of the myxosporean diseases. Further studies on the life cycle of $M$. spirosulcatus are required.

The experiment of disease mechanisms suggests that water temperature is partly responsible for disease outbreak but feeding regime does not affect the disease. This implies that water temperature is one of the key factors inducing the disease, but temperature control is not feasible in a sea cage culture system. It is unknown why the detection rate of M. spirosulcatus spores in the bile differed significantly between the constant and fluctuating temperature groups. The developmental dynamics of $M$. spirosulcatus in fish remain to be clarified. Lack of spore formations and occurrence of inflammatory responses in the spinal cord suggest that this is an accidental infection or abnormal development [9]. Alternatively, it is also possible that M. spirosulcatus migrate through the nervous tissue before settlement in the bile duct.
Generally, no chemotherapeutants and vaccines are commercially available to myxosporean diseases. Thus, the current disease control strategies are only based on the biology of myxosporeans. However, even if the actinospore stage and the alternate invertebrate host for the parasite are elucidated, it is likely impossible to prevent exposure of actinospores, because yellowtail are usually cultured in sea cages set up in the open sea. Site selection seems to be an alternative practical means of avoiding the infection, but it is required to investigate the geographical distribution of the parasite. To minimize the risk of pathogen introduction by seedlings, it is highly recommended to inspect the myxosporean infection as early as possible with the sensitive PCR diagnostic assay [9]. Further studies on the biology of M. spirosulcatus are required before a management strategy can be implemented for the myxosporean encephalomyelitis of yellowtail.

\section{Acknowledgments}

We thank Dr. Mark Freeman for reviewing this manuscript, and fish farmers in Ehime and Kagoshima Prefectures for providing the samples. This research was partially funded by Japan Fisheries Resource Conservation Association.

\section{References}

1. Coleman MP, Freeman MR (2010) Wallerian degeneration, Wlds, and Nmnat Annual Review of Neuroscience 33: 245-267.

2. S Jr, Poynton SL, West AB, Van Kruiningen HJ (1998) Epizootiology, pathology, and ultrastructure of the myxosporean associated with parasitic encephalitis of farmed Atlantic salmon Salmo salar in Ireland. Dis Aquat Organ 32: 211-225.

3. Frasca S Jr, Linfert DR, Tsongalis GJ, Gorton TS, Garmendia AE, et al. (1999) Molecular characterization of the myxosproean associated with parasitic encephalitis of farmed Atlantic salmon Salmo salar in Ireland. Dis Aquat Organ 35: 221-233.

4. Katagiri T, Hosokawa A, Maita M, Hirai M, Takagi S, et al. (2007) A new disease in cultured yellowtail Seriola quinqueradiata characterized by encephalomyelitis. Fish Pathol 42: 223-224.

5. Lom J, Dyková I (2006) Myxozoan genera: definition and notes on taxonomy, life-cycle, terminology and pathogenic species. Folia Parasitologica 53: 1-36.

6. Maeno Y, Sorimachi M, Ogawa K, Kearn GC (1995) Myxobolus spirosulcatus n. sp. (Myxosporea, Bivalvulida) infecting the bile duct of the yellowtail Seriola quinqueradiata from Japan. Syst Parasitol 31: 189-193.

7. Rodger HD, Turnbull T, Scullion FT, Sparrow D, Richards RH (1995) Nervous mortality syndrome in farmed Atlantic salmon. Vet Rec 137: 616-617.

8. Scullion FT, Scullion MG, Sparrow D, Rodger HD, Sheahan BJ (1996) Encephalitis and mass mortality of farmed salmon smolts in an isolated sea bay in Ireland. Vet Rec 138: 161-162.

9. Yokoyama H, Yanagida $\mathrm{T}$, Freeman MA, Katagiri T, Hosokawa A, et al. (2010) Molecular diagnosis of Myxobolus spirosulcatus associated with encephalomyelitis of cultured yellowtail, Seriola quinqueradiata Temminck \& Schlegel. J Fish Dis 33: 939-946.
This article was originally published in a special issue, Current and Emerging Diseases/Disorders of Fish in Aquaculture handled by Editor(s). Prof. Patrick T.K. Woo, University of Guelph, Canada; Dr. Kenneth D. Cain, University of Idaho, USA. 